\title{
Phylogenetic evidence of canine distemper virus in Serengeti's lions
}

Timm C. Harder*, Marcel Kenter*, Max J.G. Appcl', Melody E. Roelke-Parker ${ }^{\ddagger}$, Thomas Barrett ${ }^{\S}$ and Albert D.M.E. Osterhaus*II

Recently an epizootic, reported to be due to a morbillivirus infection, affected the lion population of the Tanzanian Serengeti National Park. A morbillivirus phosphoprotein $(P)$ gene fragment was amplified by $P C R$ from tissue samples of several affected lions. Sequencing of the amplificates and subsequent phylogenetic analyses revealed that a wildtype strain of canine distemper morbillivirus (CDV) was involved. Vaccination of the local domestic dog population with proven safe CDV vaccines is proposed.

Keywords: Morbillivirus; canine distemper virus; felids; Serengeti

Recently, a considerable proportion of the lion population of the Tanzanian Serengeti National Park has succumbed to a disease that closely resembles distemper in dogs and seals, which are caused by the morbilliviruses canine distemper virus (CDV) and phocine distemper virus (PDV), respectively ${ }^{1,2}$. On the basis of the observed clinical symptoms, a morbillivirus aetiology was suspected and subsequently confirmed by demonstrating immunofluorescence with morbillivirusspecific antisera in organs of dead lions, and by showing the development of morbillivirus-specific serum antibodies in affected animals (cited after ref.3). Details of the distemper outbreak in lions in the Serengeti will be reported separately (Roelke et al., in preparation). Until recently, felids were not considered natural hosts of morbilliviruses. However, in 1991 and 1992 infections with CDV-like morbilliviruses caused enzootics amongst large felids in zoos in the USA ${ }^{4}$. To acquire insight into the possible origin of the viruses involved in these outbreaks in large felids, we have conducted a phylogenetic analysis of the viruses involved. To this end, we have sequenced and compared a $P$ gene fragment of the respective morbilliviruses, which was previously shown to be informative for determining phylogenetic relationships of the presently known members of the genus Morbillivirus ${ }^{5}$.

Brain and lymphoid tissues obtained from five lions which had died in the Serengeti National Park during the outbreak (kindly provided by Dr Hans Lutz, Department of Internal Veterinary Medicine, University of Zurich, on behalf of the Messerli Foundation of Zurich, Switzerland) were processed for reverse transcription of total RNA with random hexamer

*Department of Virology, Erasmus University, P.O. Box 1738, 3000 DR Rotterdam, The Netherlands. 'J.A. Baker Institute of Animal Health, College of Veterinary Medicine, Cornell University, Ithaca, New York, NY 14853, USA. "Tanzania National Parks, Seronera Serengeti, Tanzania. sInstitute of Animal Health, Pirbright Laboratories, Ash Road, Woking, Surrey GU4 DNF, UK. Author to whom correspondence should be addressed. (Received 10 February 1995; accepted 10 February 1995) primers and subsequent PCR amplification of the relevant $P$ gene fragment using the suitable primer $\operatorname{set}^{5}$. The amplificates were identified as $P$ gene derived by Southern blot analysis using a CDV $P$ gene fragment as a probe. In the tissues of four of the five lions, the relevant $P$ gene fragment was detected (not shown). $P$ gene fragments derived from brain material of two lions were cloned and sequenced using standard techniques ${ }^{6}$. The sequences were identical and were subsequently compared to corresponding, recently determined $P$ gene fragments of other morbilliviruses. These included CDV vaccine strains (Onderstepoort and Bussell), recent CDV isolates from a dog in Europe and from a seal in Siberia (PDV-2), as well as recent isolates from a grey fox (A92-9A) and a captive black leopard (A92-6) in the USA, PDV, measles virus (MV), rinderpestvirus (RPV) and two cetacean morbilliviruses (DMV and PMV, for review sce refs 5,7$)$. Sequence alignments of the $P$ gene fragment of a Vero cell-adapted CDV isolate from a captive black leopard (A92-6) ${ }^{4}$ and a PCR amplificate obtained from brain material of a Serengeti lion (94-28/PLE) are shown in Figure 1.

From the phylogenetic tree constructed on the basis of these data, it may be concluded that the morbillivirus that caused the epizootic amongst the Serengeti lions belongs to the CDV cluster of morbilliviruses (Figure 2). The data also indicate that the viruses which caused the recent outbreaks amongst large felids in the USA and Africa are not new or separate felid morbilliviruses, but rather viruses circulating in domestic and wild carnivores that from time to time also cross species barriers into feline hosts. Similarly, evidence for CDV and PDV infections in pinniped species and for DMV and PMV infections in cetacean species was recently reported $^{2.7}$, which had apparently not been infected with these viruses in the last decades. Whether the crossing of species barriers is a natural phenomenon for morbilliviruses that has largely been overlooked in the past, or whether predisposing factors have rendered the species involved more susceptible to infections with 'foreign' morbilliviruses, remains to be determined. Efforts are in progress to isolate the CDV strain causing 
Phylogenetic evidence of canine distemper virus in Serengeti's lions: T.C. Harder et al.

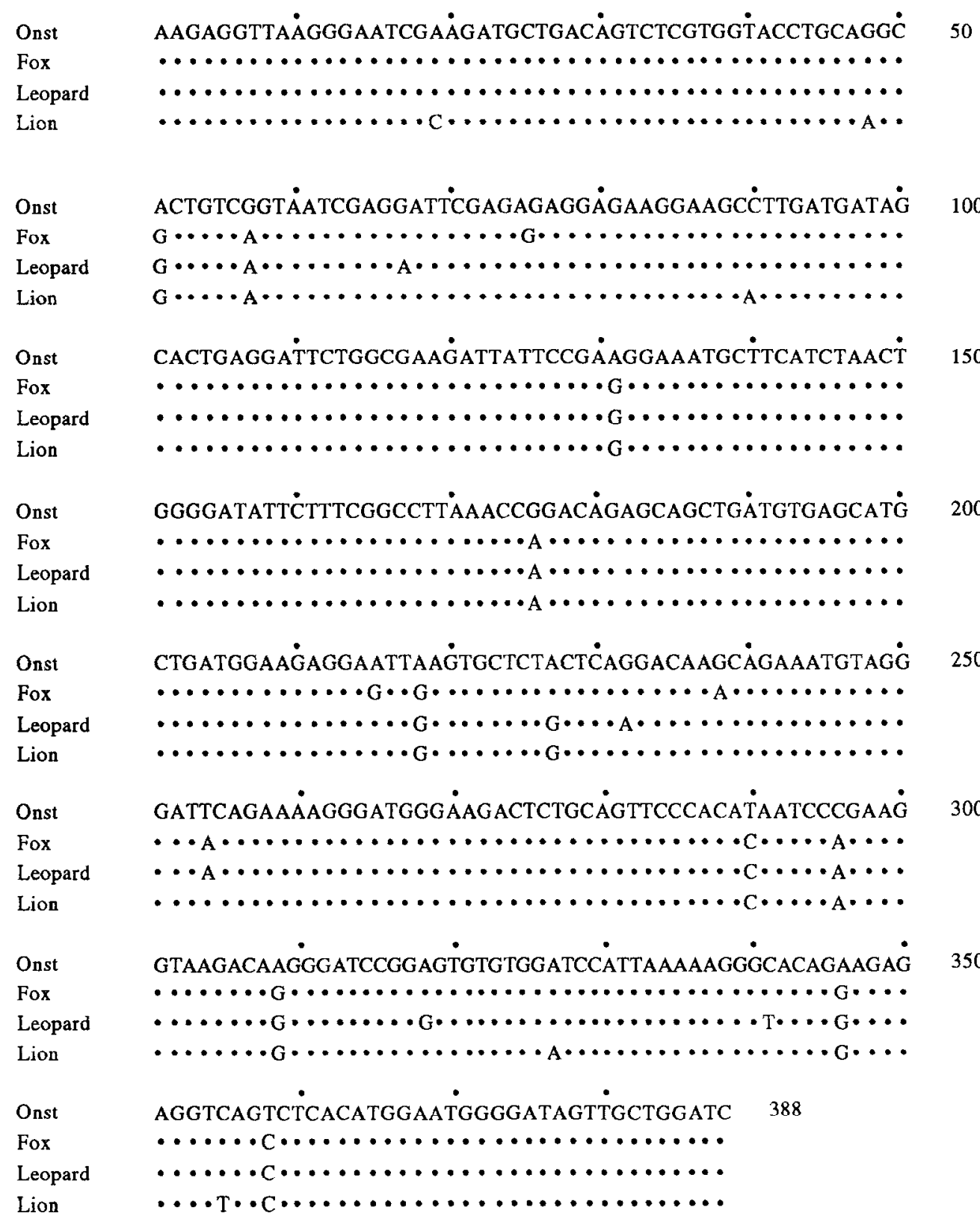

Figure 1 Sequence alignment generated by 'Pileup' of the GCG software package (version 8.0 ) of a 388 bp $P$ gene fragment (sequences of PCR primers are excluded) of the Onderstepoort (Onst) vaccine strain of canine distemper virus (Gen Bank acc. no. \#X51869), a CDV isolate of a black leopard (A92-6) from a North American zoo and of a grey fox (A92-9A) from the USA as well as a PCR amplificate obtained from brain material of a free-ranging lion of the Tanzanian Serengeti National Park (94-28/PLE). Identical nucleotides are shown as dots

mortality among lions in the Serengeti and further sequence its $\mathrm{H}$ and $\mathrm{F}$ glycoprotein genes for more detailed comparisons.

Efficient control of morbillivirus infections can be achieved by vaccination measures. However, vaccination of wildlife populations is not generally recommendable. Furthermore, use of live attenuated $\mathrm{CDV}$ vaccines in non-canid wildlife species which are highly susceptible to CDV infections, such as the lesser panda or mustelid species like the black-footed ferret, led to vaccine-induced fatal distemper. Therefore, in order to reduce the potential risk of recurrent introduction of CDV into the population of large felids and other CDV susceptible carnivores of the Serengeti, we propose to vaccinate the local domestic dog population with proven safe CDV vaccines.

\section{REFERENCES}

1 Appel, M.J.G. and Gillespie, J.H. Canine distemper virus. Virol. Monogr. 1972, 11, 1

2 Osterhaus, A.D.M.E., Groen, J., De Vries, P., UytdeHaag, F., Klingeborn, B. and Zarnke, R. Canine distemper virus in seals. Nature 1988, 335, 403

3 Morell, V. Serengeti's big cats going to the dogs. Science 1994 , 264, 1664

4 Appel, M.J.G., Yates, R.A., Foley, G.L., Bernstein, J.J., Santenelli, S., Spielman, L.D. et al. Canine distemper virus epizootic in lions, tigers, and leopards in North America. J. Vet. Diagn. Invest. 1994, 6, 277

5 Barrett, T., Visser, I.K.G., Mamaev, L., Van Bressem, M.-F. and Osterhaus, A.D.M.E. Dolphin and porpoise morbiliviruses are genetically different from phocine distemper virus. Virology 1993, 193, 1010

6 Murphy, G. and Kavanagh, T. Speeding-up the sequencing of double-stranded DNA. Nucl. Acid Res. 1988, 16, 5198 


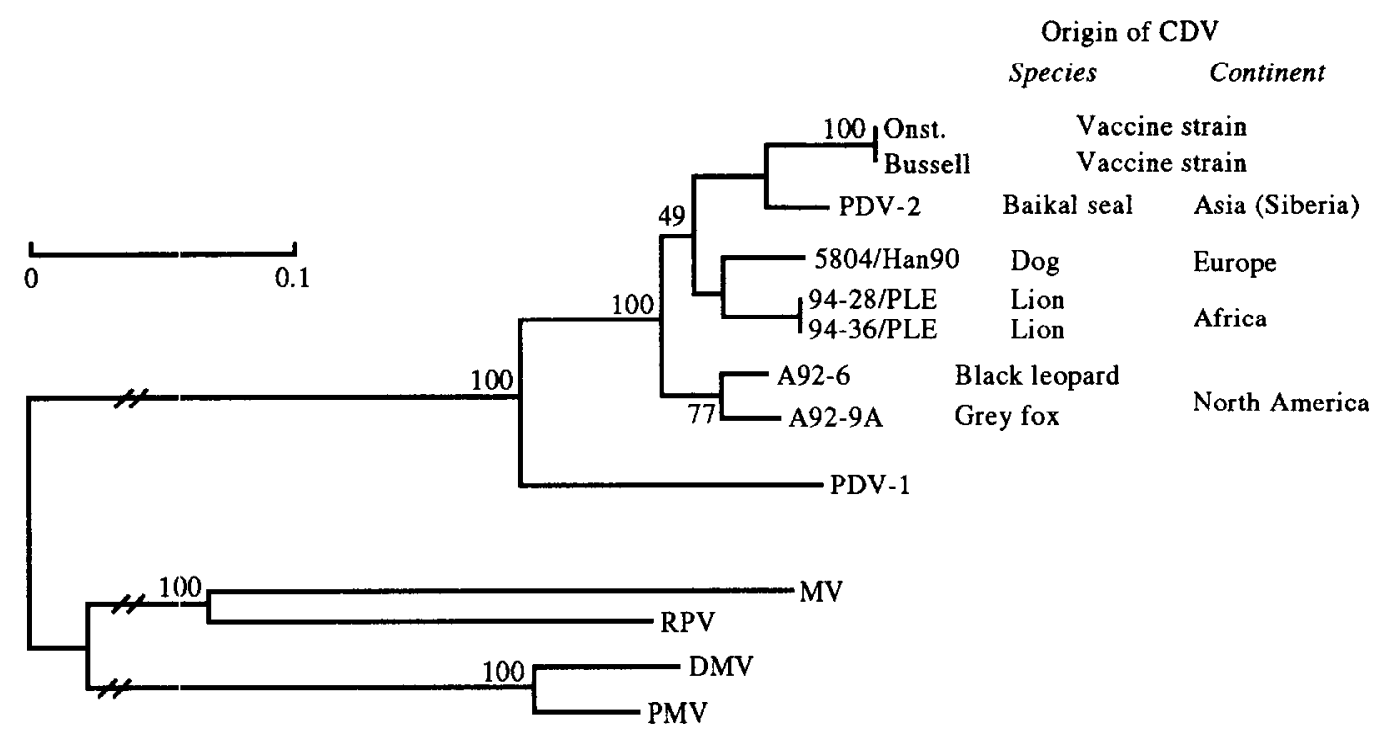

Figure 2 Phylogenetic tree, generated by the neighbor joining method ${ }^{8}$, of morbilliviruses based on analysis of a 388 bp $P$ gene fragment (excluding sequences of primers used for PCR). The robustness of the tree was statistically analysed by the bootstrap method employing 2000 replications ${ }^{9,10}$. Values of $\geq 95$ indicate statistic significance that the respective cluster is separated from the rest of the tre日. Maximum parsimony analysis of the data gave similar results (not shown). Branch lengths are proportional to the genetic distances, which were calculated by the Kimura-2-parameter method ${ }^{11}$. Sequences were aligned by using 'Pileup' of the GCG software package (release 8.0) setting gap weights to 3.0 and gap length weights to 0.1 . Within the compared fragment no gaps were observed. MV, measles virus (\#M89920); RPV, rinderpest virus (\#X68311); DMV, PMV, dolphin and porpoise morbilliviruses; PDV, phocid distemper virus (European harbour seal morbilivirus, \#D10371); ONST (\#X51869), Bussel, canine distemper virus (CDV) vaccine strains; 5804/Han90, CDV field isolate obtained from a dog in Germany; PDV-2, phocid distemper virus type-2 (Baikal seal morbillivurus); A92-6-CDV, isolate of a captive black leopard from the USA; A92-9A-CDV isolate of a grey fox from the USA; Serengeti lions 94-28/PLE and 94-36/PLE-sequence of PCR amplificates of the $P$ gene fragment generated from brain material; three, respectively two, clones were sequenced, all showed an identical sequence. Sequences were either extracted from the GenBank database (acc. no. given in brackets) or from recent publications ${ }^{5,12}$

7 Visser, I.K.G., van Bressem, M.-F. de Swart, R.L., van de Bildt, M.W.G., vos, H.W., van der Heijden, R.W.J. et al. Characterization of morbilliviruses isolated from dolphins and porpoises in Europe. J. Gien. Virol. 1993, 74, 631

8 Saitou, N. and Nei, M. The neighbor-joining method: a new method for reconstructing phylogenetic trees. Molec. Biol. Evol. $1987,4,406$

9 Felsenstein, J. Confidence limits on phylogenies: an approach using the bootstrap. Evolution 1985, 39, 783
10 Hedges, S.B. The number of replications needed for accurate estimation of the bootstrap $P$ value in phylogenetic studies. Molec. Biol. Evol. 1992, 9, 366

11 Kimura, M. A simple method for estimating evolutionary rates of base substitutions through comparative studies of nucleotide sequences. J. Molec. Evol. 1980, 16, 111

12 Mamaev, L.V., Visser, I.K.G., Harder, T.C., Belikov, S.I., Denikina, N., Liess, B. et al. Characterization of morbilliviruses in Lake Baikal seal (Phoca sibirica). J. Gen. Virol., in press 